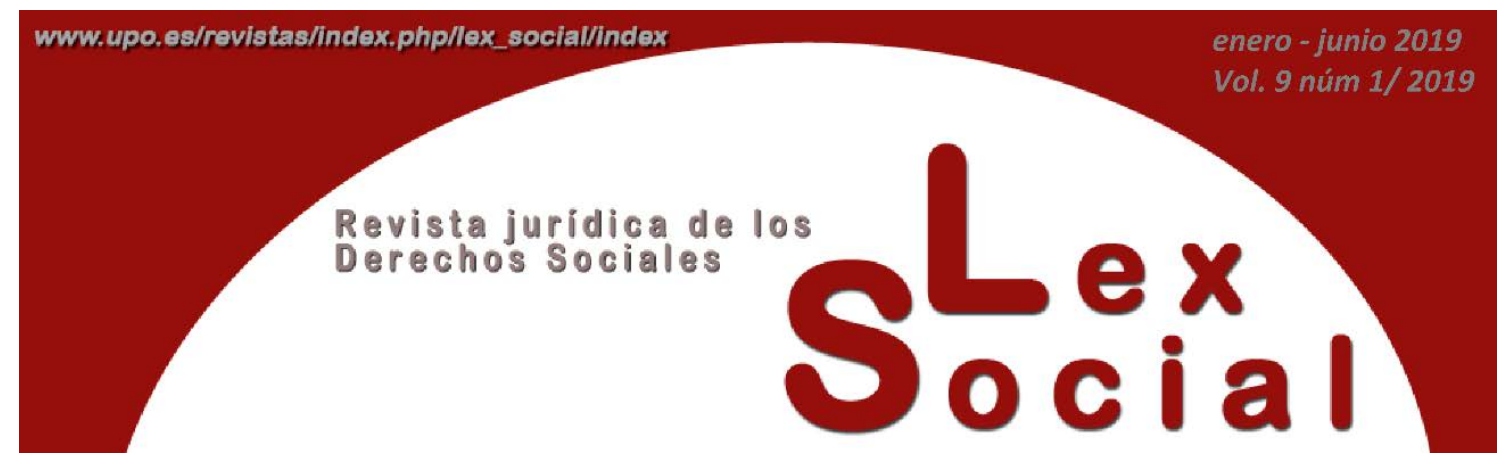

\title{
LOS DERECHOS DE PARTICIPACIÓN POLÍTICA DE LAS PERSONAS CON DISCAPACIDAD
}

\section{THE RIGHTS TO POLITICAL PARTICIPATION OF PERSONS WITH DISABILITIES}

\author{
$M^{a}$ REYES PÉREZ ALBERDI \\ Profesora Contratada Doctora de Derecho Constitucional \\ Universidad Pablo de Olavide
}

Artículo recibido el 15 de marzo de 2019

Artículo aceptado el 21 de marzo de 2019

\section{RESUMEN}

La reciente reforma de la Ley Orgánica de Régimen Electoral General ha situado a España en el aún reducido número de Estados que, en aplicación del artículo 29 de la Convención Internacional sobre los Derechos de las Personas con Discapacidad, consagra el derecho de sufragio de todas las personas con discapacidad en igualdad de condiciones con respecto a las demás y con independencia del motivo o grado de la discapacidad. Se analizan en este trabajo de manera crítica las medidas adoptadas por el legislador español para facilitar la participación de los discapacitados en la vida política, señalando algunas aporías e insuficiencias de la regulación vigente.

Palabras Clave: Participación política; personas con discapacidad; sufragio activo; cuotas electorales; igualdad y no discriminación.

\section{Abstract}


Recent changes in the Spanish Organic Law of the General Electoral Regime have placed Spain among the few States that vests person with disabilities with political participation rights on an equal basis with others, regardless the type or degree of that disability, in application of the article 29 in the International Convention on the Rights of Persons with Disabilities. In this work, the different measures passed by the Spanish legislative to facilitate the participation of persons with disabilities in political life are analysed and we point out some aporias and failures in the current legislation.

KEY WoRDS: Political participation; persons with disabilities; right to vote; electoral quotas; equality and non-discrimination.

\section{SUMARIO}

1. Introducción.

2. Los derechos de participación política en la Convención Internacional sobre los Derechos de las personas con discapacidad.

2.1. El artículo 29 de la Convención Internacional sobre los Derechos de Personas con Discapacidad.

2.2. Las Observaciones Finales sobre España de 2011

3. Medidas para facilitar el sufragio a las personas con discapacidad física o sensorial.

3.1. Accesibilidad universal de los procesos electorales.

3.2. Participación autónoma en los procesos electorales.

4. El sufragio de las personas con discapacidad intelectual o psíquica. Aporías e insuficiencias de la regulación vigente.

4.1. La incompatibilidad con el contenido esencial del derecho de sufragio.

4.2. La omisión de toda regulación de las medidas y apoyos precisos para el ejercicio del sufragio activo por las personas con discapacidades intelectuales o psíquicas.

4.3. ¿Y el sufragio pasivo? ¿Por qué no introducir cuotas electorales?

5. Bibliografía. 


\section{Introducción}

El próximo 28 de abril podrán votar en torno a 100.000 personas con discapacidad intelectual o psíquica que, hasta la modificación de la Ley orgánica 5/1985, de Régimen Electoral General efectuada por la Ley orgánica 2/2018, de 5 de diciembre (BOE, núm. 294, de 6 de diciembre de 2018, en adelante, LOREG), se encontraban privadas del derecho de sufragio por sentencia firme de incapacitación ${ }^{1}$. Esta modificación electoral ha obedecido, según se expone en la propia exposición de motivos de la ley, a la contradicción patente entre los apartados b) y c) del artículo 3.1 de la LOREG (suprimidos por la reforma) y la Convención Internacional sobre los Derechos de Personas con Discapacidad (BOE, núm. 96, de 21 de abril de 2008 en adelante, CDPD) ${ }^{2}$, dado que según el artículo 29 CDPD todas las personas con discapacidad deberán gozar de los derechos de participación política en igualdad de condiciones con las demás personas (2).

Se suma ésta a las numerosas medidas que a lo largo de las dos últimas décadas se han ido introduciendo en la legislación electoral para facilitar el derecho de sufragio a las personas con discapacidad física y sensorial (3). Lo cual contrastaba con la situación de las personas con discapacidad intelectual y mental que, por el contario, no habían recibido la ninguna atención por parte del legislador ${ }^{3}$, más allá de la privación del derecho recogida en el artículo 3 LOREG y cuya puesta en práctica por los tribunales, además, se ha regido por un cierto automatismo derivado quizás de la inexistencia de criterios o requisitos en el propio precepto que hubiesen ayudado a la aplicación judicial del mismo ${ }^{4}$.

En definitiva, España se ha situado dentro del reducido club de Estados que han eliminado de su legislación electoral la privación del sufragio a aquellas personas con capacidad jurídica modificada ${ }^{5}$. No obstante, creemos que la regulación efectuada por el legislador español dista mucho de ser perfecta, habiéndose reducido a la mera supresión

\footnotetext{
${ }^{1}$ En las últimas elecciones generales de 26 de junio de 2016, el dato exacto es de 98.488 según la respuesta de la Junta Electoral Central a la pregunta efectuada por el Comité Español de Representantes de Personas con Discapacidad (CERMI), fechada el 24 de junio de 2016.

${ }^{2}$ Hecha en Nueva York el 13 de diciembre de 2006 y en vigor en España desde el 3 de mayo de 2008 (BOE núm. 96, de 21 de abril de 2008).

${ }^{3}$ En igual sentido, L. GÁLVEZ MUÑOZ, "El régimen de la participación electoral de las personas con discapacidad en los cuarenta años de democracia”, Revista de Derecho Político, núm. 100, 2017, p. 1093.

${ }^{4}$ Entre otros muchos, J. BARRAT ESTEVE, “Discapacitados mentales y participación política: el derecho de sufragio”, en: G. Escobar ROCA y A. PÉREZ TROYA (Dirs.): Ombudsman y colectivos en situación de vulnerabilidad. Actas del III Congreso Internacional del PRADPI, Tirant lo Blanch, Valencia, 2017, p. 165.

${ }^{5}$ Según el Informe del año 2014 de la Agencia de la Unión Europea para los Derechos Fundamentales sólo 7 de los 28 Estados de la Unión: Austria, Croacia, Italia, Letonia, Países Bajos, Suecia y Reino Unido. Esté número va avanzando lentamente, sumándose España, Dinamarca, Alemania y Eslovaquia (en los dos últimos, como consecuencia de la declaración por el Tribunal Constitucional de la privación del sufragio a las personas discapacitadas). Además, Irlanda y Finlandia, no restringen el derecho de voto a las personas discapacitadas, pero sí el derecho de sufragio pasivo. Vease, AGENCIA DE LA UNIÓN EUROPEA PARA LOS DERECHOS FUNDAMENTALES: El derecho a la participación política para las personas con discapacidad: indicadores de derechos humanos, FRA, Luxemburgo, 2014, p. 40 e ÍDEM: Who will (not) get to vote in the 2019 European Parliament elections? Developments in the right to vote of people deprived of legal capacity in EU members States, FRA, Luxemburgo, 2019, pp. 3-6. .
} 
de los preceptos que les impedían el voto y la postulación a los cargos representativos ${ }^{6}$, pero sin desarrollar de manera específica medidas facilitadoras o los apoyos necesarios para poder ejercer los derechos de participación política en igualdad de condiciones con las personas con discapacidad exigidas por la CDPD ni tener en cuenta el propio contenido esencial del derecho de sufragio (4).

\section{Los derechos de participación política en la Convención Internacional sobre los Derechos de las Personas con Discapacidad}

Resulta ya un lugar común sostener que la CDPD constituye un cambio de paradigma en el tratamiento de la discapacidad ${ }^{7}$, el cual implica su consideración como una cuestión de derechos humanos ${ }^{8}$. En efecto, frente al modelo tradicional que ve la discapacidad como un rasgo personal que tiene su origen en las limitaciones de tipo funcional -física, sensorial, intelectual o mental- ocasionadas por el padecimiento de una deficiencia (alteración genética, enfermedad, trauma, accidente o cualquier otra alteración de la salud) y que convierte al discapacitado en mero objeto de protección, es decir, en receptor de un tratamiento médico con el que podría superar las limitaciones que tiene en su vida diaria y alcanzar, así, la “normalidad” y, en caso de que ello no fuera posible, la respuesta de los diferentes ordenamientos ha sido siempre la inevitable restricción de sus derechos y la sustitución de su voluntad por medio de la representación legal de sus intereses (modelo médico o rehabilitador); la CDPD parte de un modelo completamente distinto, que considera que la discapacidad no es fruto únicamente de la presencia de una limitación individual del discapacitado sino de la interacción de ésta con las barreras presentes en la sociedad que impiden el libre desarrollo de su personalidad y su participación plena y efectiva, en igualdad de condiciones con los demás (modelo social) ${ }^{9}$.

Desde esta perspectiva, el modelo social se funda en la existencia de una pluralidad de capacidades, aptitudes o fortalezas, fruto de la propia diversidad de la especie humana que no puede ser tratada de una manera homogénea por el ordenamiento jurídico, sino que necesita una respuesta adaptada a las circunstancias individuales y

\footnotetext{
${ }^{6}$ No puede olvidarse que el artículo 6 de la LOREG establece como requisito del sufragio poseer la condición de elector.

${ }^{7}$ P. CUENCA GÓMEZ, "El derecho de voto de las personas con discapacidad intelectual y psicosocial. La adaptación de la legislación electoral española a la Convención Internacional de Derechos de las Personas con Discapacidad”, Derechos y libertades, núm. 38, 2018, p. 173 y V. C. PASCUAL PLANCHUELO, "El derecho de voto de las personas con discapacidad y, en especial, de las personas con discapacidad psíquica o intelectual en Derecho Internacional. Su recepción en España”, Revista Española de Discapacidad, 4 (1), 2017, p. 107.

8 A. PALACIOS y F. J. BARIFFI, La discapacidad como una cuestión de derechos humanos. Una aproximación a la Convención Internacional sobre los derechos de las personas con discapacidad, Cinca, Madrid, 2007 y R. de ASIS ROIG, Sobre discapacidad y derechos, Dykinson, Madrid, 2013, p. 36.

${ }^{9}$ Sobre los orígenes de este modelo y sus diferencias con los modelos anteriores resulta imprescindible la consulta de A. PALACIOS, El modelo social de discapacidad: orígenes, caracterización y plasmación en la Convención Internacional sobre los derechos de las personas con discapacidad, Cinca, Madrid, 2008, pp. 103-201.
} 
elaborada con el concurso o participación de las propias personas con discapacidad. Por eso, el cumplimiento de la CDPS no se salva con el mero reconocimiento a los discapacitados de la titularidad de todos los derechos, es decir, de su plena capacidad jurídica, sino que exige la prestación de un sistema de apoyos, para aquellas personas que lo requieran, en la toma de decisiones de conformidad con los nuevos estándares del Derecho Internacional, que precisan, entre otras cuestiones el respeto de su voluntad y de sus preferencias ${ }^{10}$.

Puede deducirse sin dificultad que este cambio de paradigma tiene su reflejo en los derechos de participación política, como veremos a continuación.

\subsection{EI artículo 29 de la Convención Internacional sobre los Derechos de Personas con Discapacidad}

El artículo 29 de la CDPD garantiza a todas las personas con discapacidad sus derechos políticos en igualdad de condiciones con el resto de personas. Derechos políticos que según se desglosa en el propio precepto serían:

a) El derecho de sufragio secreto, libre e igual en elecciones y referéndums.

b) El derecho a ser elegidas para ocupar y ejercer cargos públicos representativos en todos los niveles de gobierno.

c) El derecho a designar, si así lo desean, una persona de su confianza que es preste asistencia en el momento de emitir su voto.

d) El derecho a participar en organizaciones no gubernamentales y asociaciones relacionadas con la vida política de su país, especialmente en los partidos políticos.

e) El derecho a constituir y participar a través de organizaciones no gubernamentales de personas con discapacidad que representen los intereses de estas personas en los distintos niveles de gobierno.

A su vez, como señala Pascual Planchuelo ${ }^{11}$, se deduce del propio precepto que estos derechos implican una serie obligaciones para los Estados que han incorporado a sus ordenamientos jurídicos la Convención, como son:

$1^{\text {a }}$. Deben garantizar el ejercicio de los derechos proclamados en igualdad de condiciones con las demás y, en consecuencia, deben

\footnotetext{
${ }^{10}$ Véase en este sentido la Observación General n ${ }^{\circ} .1$ del Comité de Derechos de Personas con discapacidad, de 25 de noviembre de 2013, relativa a la capacidad jurídica y A. PALACIOS, "El modelo social de discapacidad y su concepción como cuestión de derechos humanos”, Revista Colombiana de Ciencias Sociales, vol. 8, núm. 1, 2017, p. 16.

${ }^{11}$ V. C. PASCUAL PLANCHUELO, "El derecho de voto de las personas con discapacidad y, en especial, de las personas con discapacidad psíquica o intelectual en Derecho Internacional. Su recepción en España”, op. cit., p. 106.
} 
$2^{a}$. Deben garantizar que los procedimientos, instalaciones y materiales sean accesibles y de fácil comprensión para todas las personas con discapacidad.

$3^{\mathrm{a}}$. Deben proteger el secreto, la libertad y la igualdad de voto las personas con discapacidad.

$4^{\mathrm{a}}$. Deben facilitar el uso de nuevas tecnologías y tecnologías de apoyo cuando sea preciso para el ejercicio efectivo de los derechos de participación política por las personas con discapacidad.

$5^{\text {a }}$. Deben facilitar que las personas con discapacidad puedan expresar libremente su voluntad política, ayudándose, cuando sea necesario de una persona de su elección que les preste asistencia para poder emitir el voto.

$6^{\text {a }}$. Deben fomentar la participación de las personas con discapacidad en organizaciones no gubernamentales y asociaciones políticas

Y, finalmente, $7^{\mathrm{a}}$. Deben fomentar la constitución de organizaciones no gubernamentales de personas con discapacidad que representen sus intereses en todos los niveles de gobierno.

En definitiva, el artículo 29 CDPD establece un conjunto de derechos subjetivos y de obligaciones para los Estados dirigidas a asegurar la plena y efectiva participación política de las personas con discapacidad. Ahora bien, como nos recuerda Cuenca Gómez, este precepto no puede interpretarse de manera aislada en el texto de la Convención, sino en su contexto, teniendo en cuenta otras disposiciones de su articulado ${ }^{12}$. A nuestro juicio, son dos los preceptos básicos que deben tenerse en cuenta: el artículo 3 que establece los principios generales que deben orientar la aplicación de la Convención, especialmente el apartado a), es decir, los principios de respeto de la dignidad inherente, la autonomía individual, incluida la libertad de tomar las propias decisiones, y la independencia de las personas; y el artículo 12 que consagra el derecho de al igual reconocimiento como persona ante ley, es decir, el reconocimiento pleno de personalidad capacidad jurídica a las personas con discapacidad. Pues, del juego de estos 3 preceptos (artículos 3, 12 y 29 CDPD), el Comité de Derechos de Personas con Discapacidad ha deducido la incompatibilidad absoluta con este tratado de cualquier forma de privación del derecho de sufragio basada en la discapacidad intelectual o psíquica de una persona. De ahí, que entienda que las especiales dificultades que puedan encontrar estas personas para ejercer su derecho, motivadas (o al menos agravadas) no sólo por sus limitaciones personales sino también por la forma en que hemos configurado el sistema electoral y otras barreras

\footnotetext{
12 P. CUENCA GÓMEZ, "El derecho de voto de las personas con discapacidad intelectual y psicosocial. La adaptación de la legislación electoral española a la Convención Internacional de Derechos de las Personas con Discapacidad”, op. cit., p. 178.
} 
presentes en la sociedad, no deban conducir a la privación del derecho de sufragio, sino al establecimiento de un sistema de apoyos que les permitan superarlas ${ }^{13}$.

Antes de la entrada en vigor de la Convención, sin embargo, tanto las legislaciones nacionales, como en los sistemas internacionales de protección de derechos, la constatación de una incapacidad intelectual o mental era considerada un motivo válido para la exclusión del derecho de sufragio. En este sentido, podemos aún encontrar dos grandes modelos: de un lado, aquellos ordenamientos en los que la declaración de incapacidad de una persona lleva anudada necesariamente la privación automática del derecho de sufragio, sin que sea preciso una evaluación judicial expresa sobre su capacidad para ejercer este derecho (por ejemplo, Hungría); de otro, aquellos otros en los que la exclusión del sufragio debe ser declarada de manera expresa en la decisión judicial de incapacitación tras una evaluación específica de su idoneidad para el ejercicio de los derechos de participación política. Dentro de este segundo modelo, se encontraba España antes de la reciente reforma de la LOREG y es el aceptado también por los diversos instrumentos internacionales de protección de derechos anteriores a la CDPD.

En este sentido, en el ámbito universal, los artículos 21 de la Declaración Universal de los Derechos Humanos ${ }^{14}$ y 25 del Pacto de Derechos Civiles y Políticos ${ }^{15}$, que garantizan los derechos de participación política, no mencionan de manera expresa a las personas con discapacidad. Sin embargo, el Comité de Derechos Humanos de la ONU ha declarado la compatibilidad del principio de sufragio universal establecido en ambos con una restricción del derecho motivada por una incapacidad mental verificada, entendiendo por tal, aquella impuesta por una decisión judicial tras un análisis imparcial, exhaustivo e individualizado por el juez.

También, en el ámbito del Consejo de Europa, el Código de Buenas Prácticas en materia electoral dictado en el seno de la Comisión de Venecia, como la jurisprudencia del Tribunal Europeo de Derechos Humanos (TEDH) sobre el artículo 3 del Protocolo $1^{\circ}$ del Convenio Europeo de Derechos Humanos ${ }^{16}$, permiten la privación del derecho de

\footnotetext{
${ }^{13}$ Véase la Observación General nº 1 del Comité de Derechos de Personas con discapacidad, de 25 de noviembre de 2013, relativa a la capacidad jurídica, p. 14.

14 Artículo 21 de la DUDH: "1. Toda persona tiene derecho a participar en el gobierno de su país, directamente o por medio de representantes libremente escogidos. 2. Toda persona tiene el derecho de acceso, en condiciones de igualdad, a las funciones públicas de su país. 3. La voluntad del pueblo es la base de la autoridad del poder público; esta voluntad se expresará mediante elecciones auténticas que habrán de celebrarse periódicamente, por sufragio universal e igual y por voto secreto u otro procedimiento equivalente que garantice la libertad del voto.

15 artículo 25 del PIDCP: “1. Todos los ciudadanos gozarán, sin ninguna de la distinciones mencionadas en el artículo 2, y sin restricciones indebidas, de los siguientes derechos y oportunidades: a) Participar en la dirección de los asuntos públicos, directamente o por medio de representantes libremente elegidos; b) Votar y ser elegidos en elecciones periódicas, auténticas, realizadas por sufragio universal e igual y por voto secreto que garantice la libre expresión de la voluntad de los electores; c) Tener acceso, en condiciones generales de igualdad, a las funciones públicas de su país”.

${ }^{16}$ Artículo 3 del Protocolo $1^{\circ}$ al CEDH. "Derecho a elecciones libres. Las Altas Partes Contratantes se comprometen a organizar, a intervalos razonables, elecciones libres con escrutinio secreto, en condiciones que garanticen la libre expresión de la opinión del pueblo en la elección del cuerpo legislativo”.
} 
sufragio por motivos de incapacidad mental o intelectual aunque no de manera incondicionada. La Comisión de Venencia, de hecho, es mucho más estricta cuando se alegan motivos de salud mental para la restricción del sufragio, exigiendo de manera expresa su imposición mediante una decisión judicial ${ }^{17}$. Igual ocurre, como tuve ocasión de exponer en otra parte ${ }^{18}$, con el TEDH, cuya jurisprudencia deja mucho menos espacio a la doctrina del margen de apreciación de los Estados de lo que es habitual en materia de elecciones ${ }^{19}$ cuando están involucrados colectivos especialmente vulnerables, exigiendo que se acuerde solo como una medida excepcional (y no sea la regla), adoptada tras la evaluación judicial individualizada sobre la aptitud de la persona para el ejercicio del voto $^{20}$.

Respecto a la Unión Europea, aunque la Carta de Derechos Fundamentales garantiza el derecho de sufragio en las elecciones al Parlamento Europeo y en las municipales en los artículos 39 y 4021, sin embargo la determinación de sus titulares corresponde a los Estados miembros dentro de los parámetros fijados por el Derecho Europeo en el Acto relativo a la elección de los diputados al Parlamento Europeo por sufragio universal directo. No obstante, creemos que en aplicación de la doctrina establecida en el caso Delvigne (aunque fuera un caso de privación del sufragio a los presos y no de discapacitados), podría el TJUE analizar la privación del sufragio a los discapacitados al incumplirse una obligación generada por el Derecho europeo nacida del citado Acto: el respeto del principio de sufragio universal ${ }^{22}$. Mucho más si se tiene en

17 Puede consultarse en https://www.venice.coe.int/webforms/documents/default.aspx?pdffile=CDLAD(2002)023rev2-cor-spa (última visita 7/3/2019)

${ }^{18} \mathrm{M}^{\mathrm{a}} \mathrm{R}$. PÉREZ ALBERDI, "La delimitación del derecho de sufragio activo por la el Tribunal Europeo de Derechos Humanos", Revista de Derecho Político, núm. 88, 2013, p. 350.

${ }^{19}$ Sobre esta cuestión puede verse, P. SÁNCHEZ-MOLINA, "El margen de apreciación nacional en las Sentencias del Tribunal Europeo de Derechos Humanos relativas al derecho de elecciones libres”, Estudios de Deusto, núm. 62 (I), 2014, pp. 371-386.

${ }^{20}$ Su doctrina sobre la privación del derecho de sufragio por motivo de incapacidad mental ha sido establecida en la STEDH, de 20 de mayo 2010, asunto Alajos Kiss contra Hungría, reiterada en las SSTEDH, de 23 de septiembre de 2014, asunto Gajcsi contra Hungría y de 21 de octubre de 2014, asunto Harmati contra Hungría. La legislación electoral húngara, como vimos, preveía la privación automática del derecho de sufragio a toda persona incapacitada cualquiera que sea el alcance y la gravedad de la deficiencia que la ocasionó. Sobre esta STEDH puede verse F. J. BARIFFI, "Corte Europea de Derechos Humanos: Ejercicio del derecho al voto de personas sujetas a un régimen de tutela (Caso Alajos Kiss vs. Hungría)", en: F. J. BARIFFI (Coord.), Práctica clínica y litigación estratégica en discapacidad y Derechos Humanos algunas experiencias de Iberoamérica, Dykinson, Madrid, 2013, pp. 457-462.

${ }^{21}$ Artículo 39 CDFUE. "Derecho de sufragio activo y pasivo en las elecciones al Parlamento Europeo. 1. Todo ciudadano de la Unión tiene derecho de sufragio activo y pasivo en las elecciones al Parlamento Europeo en el Estado miembro en que resida, en las mismas condiciones que los nacionales de dicho Estado. 2. Los diputados al Parlamento Europeo serán elegidos por sufragio universal libre, directo y secreto".

Artículo 40 CDFUE. "Derecho de sufragio activo y pasivo en las elecciones municipales. Todo ciudadano de la Unión tiene derecho de sufragio activo y pasivo en las elecciones municipales del Estado miembro en que resida, en las mismas condiciones que los nacionales de dicho Estado".

${ }^{22}$ He analizado este asunto con mayor profundidad en M. R. PÉREZ ALBERDI: "Privación a los condenados del sufragio en las elecciones al Parlamento europeo. El principio de "sufragio universal" como obligación impuesta por el Derecho Europeo al legislador nacional en la definición de la ciudadanía política de la Unión”, en: A. M. CARMONA CONTRERAS, Construyendo un estándar europeo de derechos fundamentales, Thomson Reuters Aranzadi, 2018, pp. 189-203. 
cuenta que la Unión Europea es parte de la CDPD, siendo incluso el primer tratado internacional sobre derechos humanos ratificado por esta organización supranacional ${ }^{23}$.

No obstante, comprobamos como ninguno de estos tratados establece una prohibición absoluta de privación de voto de las personas con cualquier tipo de discapacidad, en los términos exigidos por la CDPD. Igual ocurría con la legislación electoral española como tuvo ocasión de señalar el informe general sobre España del Comité sobre Derechos de las Personas con discapacidad.

\subsection{Las Observaciones Finales sobre España de 2011}

El Comité sobre Derechos de las Personas con discapacidad dicto sus Observaciones Finales respecto al informe inicial presentado por España en 2011. En ellas, sólo se ocupa de un punto: la privación del derecho de sufragio a las personas con discapacidad intelectual o psicosocial; no abordando otras cuestiones como la accesibilidad de los procedimientos, instalaciones y materiales, los apoyos o ajustes razonables realizados por nuestra legislación o la participación de las personas con discapacidad en los partidos políticos y en organizaciones que representen sus intereses en los diferentes niveles de gobierno.

Debemos recordar que la LOREG, en su artículo 3.1. letras b) y c), preveía dos supuestos de restricción del derecho de sufragio activo. En primer lugar, el de los declarados incapaces por sentencia judicial firme, siempre que dicha sentencia declarase expresamente la incapacidad para el ejercicio del derecho de sufragio. En segundo lugar, el de las personas internadas en un hospital psiquiátrico con autorización judicial, siempre que en el juez hubiese declarado expresamente también la incapacidad para ejercer derecho de sufragio. En el segundo apartado del artículo se establecía la obligación de comunicar al Registro Civil, la incapacidad para el ejercicio de este derecho, lo que determinaba la exclusión de estas personas de las listas del censo electoral.

En puridad, el Comité expresaba su preocupación sobre el tenor literal de nuestra legislación electoral y sobre su aplicación por los tribunales ${ }^{24}$, especialmente por no respetar los nuevos estándares internacionales derivados de la CDPC. En concreto, rechaza que se pueda restringir el derecho de voto de las personas con discapacidad intelectual cuando ha sido incapacitada o internada en una institución, aun cuando mediase en ese acto la intervención judicial. Además, critica la imprecisión de los criterios aplicados por los jueces para privar a las personas del derecho de voto y que la restricción

\footnotetext{
${ }^{23}$ De hecho, el Comité Económico y Social Europeo, en su Dictamen sobre la "Comunicación de la Comisión al Parlamento Europeo, al Consejo, al Comité Económico y Social Europeo y al Comité de las Regiones - Estrategia Europea sobre Discapacidad 2010-2020: un compromiso renovado para una Europa sin barreras" tras recordar que al ser Parte de la CDPD el derecho de sufragio activo y pasivo no se puede restringir por razones de discapacidad, "pide a las instituciones Europeas y a los Estados miembros que supriman las disposiciones legislativas discriminatorias en materia de tutela, para permitir a las personas con discapacidad ejercer sus derechos políticos en igualdad de condiciones con las demás” (DOUE, C 376, de 22 de diciembre de 2011, p. 86).

${ }^{24}$ CRPD/C/ESP/CO/1, 19 de octubre de 2011, párrafos 47-48.
} 
parecía ser siempre la regla y no la excepción, dado el elevado número de personas incapacitadas que habían sido privadas del derecho de sufragio. Además, se recomienda que todas las personas con discapacidad que sean elegidas para desempeñar un cargo público dispongan de toda la asistencia necesaria, incluso asistentes personales.

Respecto a la aplicación realizada por los tribunales, la doctrina ha venido destacando que durante muchos años la privación del ejercicio del derecho de sufragio se había convertido en una mera cláusula de estilo, incluida en casi todas las sentencias de incapacitación, sin ofrecer motivo alguno que la justificase ${ }^{25}$. Como señala Rivas Vañó, en España, el tratamiento de la discapacidad ha obedecido claramente al modelo médico de sustitución y representación de la voluntad personal, entendiéndose que cuanto más se sustituye esa voluntad, mayor grado de protección se otorgaba al discapacitado ${ }^{26}$. Es por ello, que en la mayoría de los supuestos de incapacidad se optaba por la tutela, como mecanismo de incapacitación total de una persona y de sustitución de todos sus derechos, frente a la curatela, también prevista en nuestro ordenamiento como instrumento de apoyo o asistencia a la persona discapacitada a la toma de decisiones.

La necesidad de compatibilizar la legislación y la práctica judicial española con la CDPD ha llevado al Tribunal Supremo a iniciar, con la STS 228/2009, de 29 de abril, una línea jurisprudencial en los procesos sobre la capacidad de las personas en las que se analiza ésta como una cuestión de derechos fundamentales y, como tal, sujeta a una interpretación restrictiva ${ }^{27}$. Se exige así que la decisión judicial sea un traje a medida que se ajuste a las necesidades de la persona ${ }^{28}$. De ahí, que la regla general a partir de ahora deberá ser la curatela, en lugar de la tutela que quedará reservada para supuestos excepcionales $^{29}$, pasando de un régimen de sustitución en la adopción de decisiones a otro basado en el apoyo para tomarlas ${ }^{30}$.

Esta doctrina ha tenido también su reflejo en el derecho que nos ocupa. Así, a partir de la STS 421/2013, de 24 de junio, el Tribunal Supremo ha venido a exigir una evaluación concreta de la capacidad para emitir el voto y la obligación de ofrecer una justificación separada e individualizada de la privación del derecho de sufragio, que debe

\footnotetext{
${ }^{25}$ Por todos, véase S. DÍAZ ALABART, "El derecho de sufragio de las personas con discapacidad. La visión civilista”, Revista de Derecho Privado, núm. 96, 2012, pp. 14-15 y A. L. MARTÍNEZ-PUJALTE, Derechos fundamentales y discapacidad, Cinca, Madrid, 2015, p. 92. .

26 A. RIVAS VAÑÓ. "Discapacidad intelectual y derecho al sufragio: la inacción del Tribunal Constitucional ESPAÑOL”, en: V. CARUSO FONTÁN y Mª R. PÉREZ ALBERDI, Diálogos judiciales en el sistema europeo de protección de derechos, Tirant lo Blanch, Valencia, 2018, p. 274.

27 Sobre esta cuestión puede consultarse, P. BOTELLO HERMOSA, "El refuerzo de la curatela como medio idóneo de adaptación del artículo 12 de la Convención ONU sobre derechos de personas con discapacidad al Ordenamiento jurídico español”, Revista Crítica de Derecho Inmobiliario, núm. 749, 2015, pp. 1355-1369 y A. L. CAMPO IZQUIERDO, "Los procesos judiciales de capacidad a la luz de la Convención de Nueva York sobre los derechos de las personas con discapacidad”, La Ley Derecho de Familia. Revista jurídica sobre familia y menores, núm. 2, 2014, pp. 2-7.

${ }^{28}$ Entre otras muchas, SSTS 341/2014, de 1 de julio, 244/2015, de 13 de mayo y 373/2016, de 3 de junio.

${ }^{29}$ Véase, SSTS 421/2013, de 24 de junio, 298 /2017 de 16 de mayo y 596/2017, de 8 de noviembre.

${ }^{30}$ Por ejemplo, SSTS 244/2015, de 13 de mayo y 145/2018, de 15 de marzo.
} 
ser la excepción y no la regla ${ }^{31}$, "pues una cosa es que no pueda regirse por sí misma o administrar su patrimonio y otra distinta que esté impedida para ejercer correctamente el derecho de sufragio" ${ }^{32}$.

Ahora bien, ante la ausencia de criterios legales sobre dicha evaluación, ha correspondido a los jueces la determinación del nivel de capacidad considerado necesario para el ejercicio de este derecho. En este sentido, es posible encontrar una línea que podríamos calificar como excepcional, desarrollada fundamentalmente por algunas Audiencias Provinciales ${ }^{33}$, en la que las sentencias determinan un estándar bajo de capacidad y ponderan los intereses en conflicto a favor del mantenimiento del derecho de sufragio, entendiendo que solo se podría declarar la incapacidad para votar cuando se acredite que la persona no tenga capacidad para decidir, es decir, exclusivamente en supuestos de inconsciencia o de absoluta falta de conocimiento o decisión. Frente a ella, la línea jurisprudencial más extendida está conformada por las sentencias que elevan este nivel de capacidad, exigiendo a las personas con discapacidad conocimientos específicos sobre el sistema político, sobre las diferentes opciones electorales o que analizan la razonabilidad de la elección realizada ${ }^{34}$; una exigencia que no se verifica respecto al resto de los electores para su inclusión en el censo y que, a nuestro juicio, supone un claro elemento de discriminación para las personas con discapacidad.

No obstante, ninguna de estas líneas jurisprudenciales supera los estándares internacionales sobre el derecho de sufragio establecidos por el Comité que, como vimos, establece una prohibición absoluta de privación del derecho de sufragio a las personas con discapacidad. Por ello, en sus Observaciones Finales se recomendó la revisión de toda la legislación española para que todas las personas con discapacidad, independientemente de su deficiencia, de su condición jurídica o de su lugar de residencia, tengan derecho a votar y a participar en la vida pública en pie de igualdad con los demás. Y en concreto que se "modifique el artículo 3 de la LOREG, que autoriza a los jueces a denegar el derecho de voto en virtud de decisiones adoptadas en cada caso particular para que todas las personas con discapacidad tengan derecho a votar".

Mandato que ha cumplido el legislador, a nuestro juicio de manera bastante deficiente, con la reciente reforma de LOREG. Pasamos a ver a continuación, las medidas

\footnotetext{
${ }^{31}$ En el desarrollo de esta línea jurisprudencial, incidió notablemente la Instrucción de la Fiscalía General del Estado 3/2010, de 29 de noviembre, sobre la necesaria fundamentación individualizada de las medidas de protección o apoyo en los procedimientos sobre determinación de la capacidad de las personas, disponible en https://www.fiscal.es/fiscal/PA_WebApp_SGNTJ_NFIS/descarga/INSTRUCCION\%2032010.pdf?idFile=0bd5f429-1a9c-42f7-a7f1-46991eb20944 (última visita, 8/3/2019).

32 Reiterada en las SSTS 341/2014, de 1 de julio y 530/2017, de 27 de septiembre.

${ }^{33}$ Véanse en este sentido, las SAP Ciudad Real, de 24 de octubre de 2012 y las SSAP de Barcelona de 13 de marzo de 2014, de 19 de noviembre de 2014, de 18 de marzo de 2015, de 10 de noviembre de 2015, de 27 de mayo de 2016, de 12 de julio de 2016 o de 8 de noviembre de 2018.

${ }^{34}$ Por ejemplo, las SSAP de Burgos, de 27 de marzo de 2015 y de Barcelona de 24 de mayo de 2018. Es el criterio seguido también por el Tribunal Supremo, en las SSTS 181/2016, de 17 de marzo; 373/2016, 3 de junio y 530/2017, de 27 de septiembre y ha sido ratificado por el Tribunal Constitucional en el ATC 196/2016, de 28 de noviembre.
} 
vigentes en nuestro ordenamiento jurídico para facilitar el derecho de sufragio a las personas con discapacidad de cualquier tipo.

\section{Medidas para facilitar el sufragio a las personas con discapacidad física o sensorial}

Son varios los artículos de nuestra Constitución que debemos tener en cuenta en la regulación de los derechos fundamentales de las personas con discapacidad. De un lado, el artículo $14 \mathrm{CE}$ se refiere a la prohibición de una serie de motivos o razones concretos de discriminación (raza, sexo, religión, opinión o cualquier otra condición o circunstancia personal o social) que representa una explícita interdicción de determinadas diferencias históricamente muy arraigadas y que han situado, tanto por la acción de los poderes públicos como por la práctica social, a sectores de la población en posiciones, no sólo desventajosas, sino contrarias a la dignidad de la persona que reconoce el artículo 10.1 $\mathrm{CE}^{35}$. No obstante, esta referencia expresa a tales motivos o razones de discriminación no implica el establecimiento de una lista cerrada de supuestos , ${ }^{36}$ como se desprende del hecho de que el precepto mencione a cualquier otra circunstancia personal o social, entre las que el Tribunal Constitucional ha considerado la discapacidad $^{37}$. La inclusión dentro de este catálogo de circunstancias personales en las que está en juego la dignidad de la persona impone un canon de control de constitucionalidad más estricto fundado en la idea de parificación. Es decir, el tratamiento diferenciado otorgado cuando se encuentran involucradas estas categorías sospechosas de discriminación debe ir dirigido a la integración e inclusión social de la persona con discapacidad $^{38}$.

De otro lado, el artículo 9.2 CE establece un mandato a los poderes públicos para conseguir la igualdad efectiva de los colectivos que se encuentren en una especial situación de vulnerabilidad y el artículo 49 CE, pese a su desafortunada redacción (al utilizar el término “disminuidos”) fija los objetivos que han de seguir las políticas públicas relativas a las personas con discapacidad (previsión, tratamiento, rehabilitación e integración) postulando, en palabras de Álvarez García ${ }^{39}$, un paradigma mixto o híbrido, es decir, un modelo en el que se pone de manifiesto el carácter limitado de la óptica médica, a la que sin duda se sigue otorgando un papel relevante, por lo que deberá ser complementado con acciones positivas de los poderes públicos para asegurar el libre desarrollo de la personalidad de los ciudadanos con discapacidad así como el pleno disfrute de los derechos fundamentales.

\footnotetext{
${ }^{35}$ SSTC 128/1987, de 16 de julio, FJ 5; 166/1988, de 26 de septiembre, FJ 2; 145/1991, de 1 de julio, FJ 2.

36 STC 75/1983, de 3 de agosto, FJ 6.

37 STC 269/1994, de 3 de octubre, FJ 4; 10/2014, de 10 de enero, FJ 4, 18/2017, FJ3 y 3/2018, de 22 de enero, FJ 5, entre otras muchas.

${ }^{38}$ Por todas, STC 126/1997, de 3 de julio, FJ 8.

${ }^{39}$ H. ÁLVAREZ GARCÍA, “La tutela constitucional de las personas con discapacidad”, Revista de Derecho Político, núm. 100, 2017, p. 1040.
} 
En la actualidad, el desarrollo de esas políticas públicas sobre discapacidad se encuentra en el Real Decreto-Legislativo 1/2013, de 29 de noviembre, por el que se aprueba el Texto Refundido de la Ley General de Derechos de las Personas con Discapacidad (BOE, núm. 289, de 3 de diciembre de 2013). Un texto en el que se refunden las tres leyes que, por el momento, se han ocupado de esta materia: la Ley 13/1982, de 7 de abril, de 1982 de Integración Social de las personas con discapacidad (BOE, núm. 103, de 30 de abril de 1982); la Ley 51/2003, de 2 de diciembre, de Igualdad de Oportunidades, No Discriminación y Accesibilidad Universal de las personas con discapacidad (BOE, núm. 289, de 3 de diciembre) y, por último, la Ley 49/2007, de 26 de diciembre, por la que se establece el Régimen de Infracción y sanciones en Materia de Igualdad de Oportunidades, No Discriminación y Accesibilidad Universal de las personas con discapacidad (BOE, núm. 310, de 27 de diciembre de 2007). No podemos detenernos en el análisis pormenorizado de las medidas que se fueron introduciendo en nuestra legislación por todas estas normas ${ }^{40}$, pero sí aclarar que el objetivo de estas normas fue el de adaptar el sistema jurídico español a las exigencias de modelo social presente en la CPDC, suprimiendo todos los obstáculos y favoreciendo las condiciones que garanticen la participación plena y efectiva en igualdad de condiciones con los demás. En este sentido, el Texto Refundido de 2013 sienta las bases para desarrollar los dos grandes principios sobre los que se funda la Convención de Nueva York: el de accesibilidad universal y la autonomía en la toma de decisiones por las personas con discapacidad, lo que necesariamente implicará el establecimiento todo un sistema de apoyos y asistencias a la persona con discapacidad para que pueda formar y expresar esa decisión autónoma.

Ambos principios se encuentran íntimamente relacionados, así, por accesibilidad universal debemos entender "la condición que deben cumplir los entornos, procesos, bienes, productos y servicios, así como los objetos instrumentos, herramientas y dispositivos, para ser comprensibles, utilizables y practicables por todas las personas en condiciones de seguridad y comodidad y de la forma más autónoma y natural posible” (artículo 2.k. del Texto Refundido 1/2013). En definitiva, para alcanzar una sociedad inclusiva y sin barreras, es imprescindible adoptar como principio de actuación la transversalidad de las políticas públicas e implementar una política de diseño universal, es decir, para todas las personas, aunque ello no podrá excluir, lógicamente, los apoyos necesarios para las personas que lo necesiten ${ }^{41}$.

En relación a los derechos de participación política, el Texto Refundido 1/2013 se mantiene en el terreno de los principios, dejando a la normativa electoral su desarrollo.

\footnotetext{
${ }^{40}$ Puede encontrarse ese análisis en el trabajo arriba citado de ÁLVAREZ GARCÍA, op. cit., pp. 10481052 y L. GÁLVEZ MUÑOZ, El derecho de voto de los discapacitados y otras personas vulnerables, Tirant lo Blanch, Valencia, 2009 y, más recientemente, "El régimen de la participación electoral de las personas con discapacidad en los cuarenta años de democracia”, op. cit., pp. 1076-1085.

${ }^{41}$ F. ALONSO LÓPEZ, "Los ejes determinantes de las políticas de igualdad de oportunidades. La accesibilidad universal y el diseño para todos”, en: R. DE LORENZO y LÓPEZ BUENO, L. C. (Coords.), Tratado sobre discapacidad, Thomson Reuters Aranzadi, Madrid, 2007, pp. 1219 y 122.
} 
De ahí, que el artículo 53 únicamente disponga que "las personas con discapacidad podrán ejercer el derecho de participación en la vida política y en los procesos electorales en igualdad de condiciones que el resto de los ciudadanos conforme a la normativa en vigor” y que "para ello las administraciones públicas pondrán a su disposición los medios y recursos que precisen”. Veamos a continuación qué desarrollo se ha dado a este precepto.

\subsection{Accesibilidad universal de los procesos electorales}

El Real Decreto 422/2011, de 25 de marzo, por el que se aprueba el Reglamento sobre las Condiciones Básicas para la Participación de las Personas con Discapacidad en la Vida Política y en los Procesos Electorales (BOE, núm. 76, de 30 de marzo de 2011), estipula reglas relativas a los locales electorales, la información electoral, las campañas electorales y el transporte a los locales electorales.

Respecto a los locales electorales, la norma establece la obligación de que todos los locales sean accesibles para las personas con discapacidad, lo que incluye que no tengan barreras u obstáculos que dificulten o impidan el ejercicio de derecho de sufragio al elector con algún tipo de discapacidad motriz o sensorial, una adecuada señalización de las secciones y las mesas electorales y la accesibilidad y cercanía a la mesa de un espacio privado donde se garantice la privacidad para la emisión del voto. Esta es la regla general, pero en el caso de que los Ayuntamientos no puedan proponer espacios accesibles, se permite que la Junta Electoral competente (es decir, la Junta Provincial) adoptar las medidas necesarias para garantizar dicha accesibilidad durante la jornada electoral (artículos 3 y 8). Cuando ello no ha sido posible, la Junta Electoral Central, por acuerdo de 15 de julio de 1999, avaló una práctica extendida consistente en que el Presidente de la mesa electoral se desplaza a la puerta del colegio electoral con la urna para realizar allí la identificación del elector y el depósito del voto en la urna. Sin embargo, no nos parece una medida que asegure el ejercicio del derecho de sufragio en igualdad de condiciones, porque, de un lado, visibiliza a la persona con discapacidad dándole un tratamiento diferente respecto a los demás electores y, de otro, disminuye las garantías del proceso electoral, que exige que la votación se realice en un espacio único y que el elector pueda realizar en privacidad el conjunto de operaciones electorales, tales como el examen y la selección de la papeletas de las distintas candidaturas, su introducción en el sobre, etc. ${ }^{42}$

Se prevé además la obligación de elaborar en formato accesible para las personas con discapacidad auditiva y sordociegas toda la información institucional sobre los procedimientos electorales realizada en páginas web de las administraciones públicas, la campaña institucional en soporte audiovisual para dar a conocer la fecha de las elecciones así como los diversos procedimientos de votación, los servicios de atención telefónica

\footnotetext{
42 En igual sentido, A. L. MARTÍNEZ-PUJALTE, Derechos fundamentales y discapacidad, op. cit., pp. 102-103.
} 
que se establezcan (por ejemplo para tramitar el voto accesible) y la información y procedimientos censales (artículos 5 y 10).

Con relación a la campaña electoral, se exige que sean accesibles también todos los locales oficiales y espacios públicos en los que se desarrollen actos de campaña electoral así como la propaganda electoral enviada por las candidaturas y los espacios gratuitos de propaganda electoral cedidos a las mismas por las emisoras de radio y televisión de titularidad pública (artículos 6 y 7) y corresponderá a la Junta Electoral de Zona velar por el cumplimiento de este mandato ${ }^{43}$.

Finalmente, se contempla la posibilidad de proporcionar a las personas con discapacidad motriz que lo soliciten medios de transporte gratuitos y adecuados para su desplazamiento al colegio electoral, aunque de manera muy limitada, pues se supedita a la ausencia de transporte público accesible al local electoral y a la disponibilidad presupuestaria (artículo 11).

\subsection{Participación autónoma en los procesos electorales}

La normativa electoral prevé tres procedimientos específicos de votación -el voto asistido, el voto accesible y el voto por correo en caso de electores con una enfermedad o discapacidad que les impida trasladarse a la oficina postal- así como una serie de medidas para garantizar la participación autónoma en los procesos electorales de los miembros de las mesas electorales y de los propios electores que tengan algún tipo de discapacidad física o sensorial. No podemos extendernos, en un trabajo de estas características, en la exposición al detalle de cada uno de estos procedimientos, por lo que nos limitaremos a dar cuenta sucinta de sus rasgos característicos esenciales ${ }^{44}$.

Los dos primeros procedimientos de votación son de carácter presencial, es decir, en la propia mesa electoral y vienen regulados en el artículo 87 de la LOREG. El voto asistido es un procedimiento muy sencillo que está previsto, además de para las personas con alguna discapacidad física o sensorial que le impida seleccionar la papeleta e introducirla en el sobre y en la urna de manera autónoma, para las personas que no saben leer. En estos casos, se permite que una persona de confianza asista al elector discapacitado en el momento de confeccionar su voto. De esta escueta regulación se deduce que el elector dispone de la libertad más absoluta para elegir a la persona que va a auxiliarle en las operaciones electorales, no exigiéndose ninguna representación legal o poder notarial expreso, ni ningún grado de parentesco u otra relación específica con el elector, es más, ni siquiera que se encuentre también inscrito en las listas del censo electoral. No obstante, este procedimiento plantea necesariamente una disminución de las garantías constitucionales del sufragio, pues obliga a desvelar a un tercero el contenido

\footnotetext{
${ }^{43}$ Véase acuerdos de la Junta Electoral Central de 19 de mayo 2011, de 12 y 26 de mayo de 2016 y de 8 de junio de 2016 sobre esta cuestión.

${ }^{44}$ Me he extendido sobre estos procedimientos en $\mathrm{M}^{\mathrm{a}}$. R. PÉREZ ALBERDI, El derecho fundamental a participar en los asuntos públicos, Congreso de los Diputados, Madrid, 2013, pp. 214-218 y 223-224.
} 
del mismo, con los riesgos que ello puede plantear para la libertad de voto. En este sentido, el papel de la mesa resulta imprescindible parar garantizar que el voto emitido responda efectivamente a la voluntad del elector, especialmente del Presidente de la misma, que tiene asignada la misión de asegurar la libertad de los electores (artículo 90.1 LOREG).

El voto accesible es un procedimiento previsto para los electores con discapacidad visual que conozcan el sistema de lectoescritura Braille (el resto tendrá que utilizar el procedimiento anteriormente descrito) que garantiza plenamente que estas personas puedan votar con total autonomía y en igualdad de condiciones con los demás ${ }^{45}$. Se basa en la utilización de papeletas y sobres que el resto de los electores a los que se acompaña con una documentación complementaria que permitirá la confección autónoma del voto por parte del elector invidente.

El último de los procedimientos enunciados es una modalidad de voto por correo que se encuentra prevista en el artículo 72.c) de la LOREG para las personas enfermas o con una discapacidad que les impida formular la solicitud de este tipo de voto en las oficinas del servicio postal. Se trata de un procedimiento muy complejo, que exige la intervención de un facultativo médico, el desplazamiento de un notario al lugar donde se encuentre el elector, normalmente su domicilio o un centro de salud, para otorgar mediante escritura un poder de representación a una persona de confianza del elector para que tramite su solicitud de voto por correo ${ }^{46}$.

En cuanto a las medidas establecidas por la normativa electoral para garantizar la participación autónoma en las mesas electorales, el Real Decreto 422/2011 impone a la Administración la obligación de proporcionar a las personas con discapacidad auditiva que hayan sido nombradas como miembros de mesa electoral un servicio gratuito de interpretación de la lengua de signos a través del correspondiente intérprete, como apoyo complementario durante la jornada electoral. Sin embargo, es de lamentar que no se haya previsto en la legislación electoral ningún ajuste razonable que permita la intervención

\footnotetext{
${ }^{45}$ La LOREG únicamente remite al Gobierno, previo informe de la Junta Electoral Central, de la regulación de un procedimiento específico que garantice el secreto de voto de los electores invidentes. Mandato que se hizo efectivo con el Real Decreto 1612/2007, de 7 de diciembre, por el que se regula un Procedimiento de Voto Accesible (BOE, núm. 294, de 8 de diciembre de 2007), desarrollado por la Orden del Ministerio del Interior 3817/2007, de 21 de diciembre, por la que se desarrolla el Procedimiento de Voto Accesible que facilita a las personas con discapacidad el derecho sufragio (BOE; núm. 310, de 27 de diciembre de 2007).

${ }^{46}$ El artículo 72.c) de la LOREG ha sido desarrollado por el artículo 8.1. del Real Decreto 605/1999, de 16 de abril, de Regulación Complementaria de los Procesos Electorales (BOE, núm. 92, de 17 de abril de 1999) y por las Instrucciones de la Junta Electoral Central /1992, de 10 de febrero, de la Junta Electoral Central, en relación con el voto por correo de las personas que se encuentren en situación de enfermedad o incapacidad que le impida la formulación personal de la solicitud de la documentación a que se refiere el artículo 72 de la LOREG (BOE, núm. 39, de 14 de febrero de 1992);de 26 de abril de 1993, sobre certificado médico oficial y gratuito a que se refiere el artículo 72.c) de la LOREG (BOE, núm. 101, de 28 de abril de 1993) y también de 26 de abril de 1993, sobre la comprobación por la Junta Electoral competente de la concurrencia de las circunstancias a que se refiere el artículo 72.c) de la LOREG (BOE, núm. 101, de 28 de abril de 1993).
} 
como miembros de las mesas a las personas con discapacidad visual, habiéndose denegado dicha participación por la falta de adaptación de la normativa que les permita el desarrollo correcto de las funciones encomendadas, pese a los reiterados acuerdos de las Junta Electoral Central instando al Gobierno en cumplimiento de lo dispuesto en la Disposición Final Quinta de la Ley 51/2003, de 2 de diciembre, de Igualdad de Oportunidades, No Discriminación y Accesibilidad Universal de las personas con discapacidad $^{47}$.

Por último, el artículo 4.3 del Real Decreto 422/2011 establece la obligación de los miembros de la mesa electoral de velar porque los electores con discapacidad puedan ejercer su derecho de voto con la mayor autonomía posible adoptando para ello los ajustes razonables que sean necesarios. En los sucesivos Manuales elaborados como Instrucciones para los miembros de la mesa electoral por el Ministerio del Interior, bajo supervisión de la Junta Electoral Central, no se especifica ninguno de estos posibles ajustes, ni siquiera como un catálogo abierto que no excluyese otras medidas necesarias. No obstante, en la página web oficial de los procesos electorales se establece una serie de recomendaciones generales dirigidas a los miembros de la mesa sobre cómo y cuándo deben dirigirse a las personas con discapacidad, el tipo de ofrecimientos o ayudas que se les puede proporcionar o cómo debe desarrollarse el proceso comunicativo con electores u otros medios de mesa con discapacidad auditiva ${ }^{48}$.

\section{El sufragio de las personas con discapacidad intelectual o psíquica. Aporías e insuficiencias de la regulación vigente}

La única mención que se había realizado en la normativa electoral a las personas con discapacidad de tipo intelectual o psicosocial era la del artículo 3 de la LOREG en el que, como sabemos, se permitía la exclusión del derecho de sufragio por medio de sentencia o autorización judicial expresa. La reciente reforma de dicha ley, eliminando los supuestos de incapacidad electoral de naturaleza civil, se ha debido a una iniciativa legislativa presentada por la Asamblea de Madrid, en la que se preveía la supresión de los apartados b y c del artículo 3 LOREG y, además, una Disposición Adicional conforme a la cual: "a partir de la entrada en vigor de la Ley de modificación de la LOREG para adaptarla a la Convención Internacional sobre los Derechos de las Personas con Discapacidad, quedan sin efecto las limitaciones en el ejercicio del derecho de sufragio establecidas por decisión judicial fundamentadas jurídicamente en el apartado 3.1. b) y c) de la LOREG ahora suprimidos. Las personas a las que se les hubiere limitado o anulado su derecho de sufragio por razón de discapacidad quedan reintegradas plenamente en el mismo por ministerio de la Ley”.

\footnotetext{
${ }^{47}$ Véase los Acuerdos de la Junta Electoral Central de 29 de febrero de 2000, 24 de marzo de 2008, de 3 y 20 de noviembre de 2011 y de 8 de junio de 2016.

${ }_{48}$ Véase http://www.infoelectoral.mir.es/recomendaciones-generales-para-integrantes-de-las-mesaselectorales-las-personas-con-discapacidad-y-la-jornada-electoral (última vista 10/3/2019).
} 
La tramitación parlamentaria de esta iniciativa ha demostrado el elevado grado de consenso de todas las formaciones políticas ${ }^{49}$. De hecho, en el Congreso de los Diputados, sólo se presentaron dos enmiendas: la primera del Grupo Popular ${ }^{50}$, rechazada por la Ponencia, se transformó durante las deliberaciones de la Comisión Constitucional, en una enmienda transacional para lograr el acuerdo por unanimidad de todos los grupos consistente en añadir un apartado $2^{\circ}$. al artículo 3 que dispone lo siguiente: "Toda persona podrá ejercer su derecho de sufragio activo, consciente, libre y voluntariamente, cualquiera que sea su forma de comunicarlo y con los medios de apoyo que requiera”, que añade cierta oscuridad al precepto, pues ¿significa ello que la Mesa podrá negarse a aceptar el voto de una persona a la que considera que no emite el voto de manera consciente? A nuestro modo de ver eso supondría una enorme disminución de las garantías del sufragio y resultaría incompatible con la práctica electoral existente, a favor del ejercicio del derecho, que impide a la mesa rechazar el voto de un elector inscrito en las listas del censo, salvo que considere que se está ejerciendo sobre él alguna coacción o intimidación sobre él, en cuyo caso se deberá poner en conocimiento del Ministerio Fiscal dicha irregularidad por si fuera constitutiva de un delito electoral.

Dichas dudas interpretativas se le han planteado también a la Junta Electoral Central y le han llevado a dictar la, a nuestro juicio en parte desacertada, Instrucción 5/2019, de 11 de marzo, sobre aplicación de la modificación de la LOREG llevada a cabo por la Ley Orgánica 2/2018, de 5 de diciembre, para garantizar el derecho de sufragio de todas las personas con discapacidad (BOE, núm. 62, de 13 de marzo de 2019). En ella, defiende, como nosotros, que los miembros de la mesa no podrán impedir que se introduzca en la urna el voto de una persona con aparente discapacidad inscrita en las listas del censo electoral, aunque consideren que no lo está ejerciendo de forma consciente. Ahora bien, y de ahí nuestra sorpresa, lo podrá hacer constar en el acta de la sesión, identificando al elector en la misma únicamente con el número del Documento que aporte para su identificación. ¿Qué sentido tiene esta declaración de constancia que

49 La tramitación $\quad$ puede consultarse http://www.congreso.es/portal/page/portal/Congreso/Congreso/Iniciativas?_piref73_2148295_73_133543 7 1335437.next_page=/wc/servidorCGI\&CMD=VERLST\&BASE=IW12\&PIECE=IWA2\&FMT=INITX D1S.fmt\&FORM1=INITXLUS.fmt\&QUERY=\%28I\%29.ACIN1.+\%26+\%28LEY+ORGANICA+DE+R EGIMEN+ELECTORAL+GENERAL\%29.OBJE.\&DOCS=11-11 (última visita 10/3/2019)

${ }^{50}$ En dicha enmienda se mantenía la posibilidad de restringir el derecho de sufragio en los procesos de modificación de la capacidad, pero limitando las posibilidades de actuación de los jueces según el criterio estableció por la línea de interpretación restrictiva y excepcional dentro de la práctica judicial que hemos comentado en el epígrafe 2.2. En concreto, se proponía lo siguiente: "Se modifica el apartado b) del punto primero del artículo 3: “b) Las personas con la capacidad de obrar modificada judicialmente en virtud de sentencia judicial firme, siempre que la misma así lo declare expresamente, por carecer de consciencia o absoluta falta de capacidad de conocimiento o decisión que les impida el ejercicio de tal derecho.” 2. Se suprime el apartado c) del punto primero del artículo 3. 3. Se modifica el punto segundo del artículo 3 de la siguiente forma: “2. A los efectos previstos en este artículo, los Jueces o Tribunales que entiendan de los procedimientos judiciales de modificación de la capacidad de obrar o internamiento deberán pronunciarse expresamente sobre la falta de capacidad para el ejercicio del sufragio de forma motivada, evaluando de forma individualizada este tipo de falta de capacidad. En el supuesto de que ésta sea apreciada, lo comunicarán al Registro Civil para que se proceda a la anotación correspondiente”. 
individualiza al elector con discapacidad cuando la legislación electoral recientemente aprobada no ha previsto ningún grado de capacidad para ejercer el derecho de voto y, por lo tanto, no se va a poder impugnar por este motivo el resultado electoral? Cuestión distinta es que creamos que la ley orgánica electoral hubiera debido tener otro contenido, como veremos en el próximo apartado.

En el Senado, únicamente se presentó una enmienda por el Grupo Parlamentario Unidos Podemos-En Comú Podem-En Marea, precisamente para devolver a la proposición de ley su redacción original, pero fue retirada. Por tanto, el texto final incluyó la enmienda acordada por el Congreso de los Diputados.

Pese a ese elevado grado de consenso en la aprobación de la reforma, creemos que adolece de graves inconsistencias y es del todo insuficiente para garantizar el ejercicio de los derechos de participación política de las personas con discapacidad intelectual o psicosocial en igualdad de condiciones con los demás. En concreto, pensamos que es incompatible con el contenido esencial del propio derecho de sufragio y que omite cualquier tipo de ajuste razonable o alguna medida de apoyo que pueda facilitar la formación y la emisión del voto o el ejercicio del cargo representativo por parte de las personas con este tipo de discapacidad.

\subsection{La incompatibilidad con el contenido esencial del derecho de sufragio}

De la definición del Estado como democrático (artículo 1.1 CE) deriva la exigencia de que todos los miembros de una comunidad política deban ser titulares de los derechos de participación política. En España, dicha participación se atribuye a todos los ciudadanos (artículo $23 \mathrm{CE}$ ). En ese “todos”, como vimos, se incluyen capaces y discapacitados (artículo 49 CE). Ahora bien, como nos recuerda Presno Linera, el hecho de que todos sean titulares no significa necesariamente que todos los ciudadanos puedan ejercer todas las facultades que integran el contenido el derecho, en concreto, emitir el voto $^{51}$.

Precisamente, una condición inherente a la idea de participación es la capacidad de autodeterminación política, es decir, "la posibilidad de comprender las diferentes opciones y de discriminar entre ellas las que se consideran preferibles para la orientación de la sociedad" 52 . Sin ese presupuesto mínimo, no puede hablarse de participación libre.

\footnotetext{
${ }^{51}$ Pero incluso los que no pueden votar sí pueden ejercer parte del objeto del derecho, dado que tienen la posibilidad de llevar a cabo las acciones necesarias para garantizar en su momento la emisión del voto, por ejemplo, las acciones para solicitar la reintegración o modificación de su capacidad jurídica modificada si variase la situación que originó su adopción (artículo 757 de la Ley 1/2000 de Enjuiciamiento Civil). Véase M. A. PRESNO LINERA, "El derecho de voto como derecho fundamental” Revista Mexicana de Derecho Electoral, núm. 2, 2012, pp. 134-135 y, en el mismo sentido, M. LEÓN ALONSO, "Los derechos de participación política de las personas con discapacidad: el derecho al voto”, Revista Europea de Derechos Fundamentales, núm. 24, 2014, p. 172.

52 M. A. PRESNO LINERA, "La titularidad del derecho de participación política”, Boletín Mexicano de Derecho Comparado, núm. 104, 2002, p. 523. Sobre la autodeterminación política como contenido del
} 
La capacidad política, por tanto, sería un elemento necesario de la delimitación o definición del propio derecho fundamental, cuyo alcance correspondería determinar al Legislador Orgánico. Y, dado que este derecho se configura como un derecho personalísimo, no puede ejercerse por sustitución de otra persona por lo que la única alternativa es la restricción del derecho de sufragio a aquellas personas que carezcan de la mínima capacidad volitiva o intelectiva.

Es más, lo contrario supone una instrumentalización lesiva de la dignidad de la persona discapacitada que, en el mejor de los casos no ejercerá nunca el derecho o, en cualquier otro, será utilizada por terceros. Así nos expone Gómez-Riesco que ha venido sucediendo en los supuestos de solicitud de poderes electorales para el voto por correo de personas que no se pueden desplazar a la mesa electoral. Relata que ocurre a veces que cuando el notario visita a la persona que va a otorgar el poder electoral en su domicilio, se da cuenta que ésta carece realmente de la capacidad natural de querer y entender suficiente e, incluso, de la voluntad de votar y de que, entonces, el requerimiento para otorgar el poder electoral no ha partido del posible votante, sino de la persona a la que supuestamente va a designar como apoderado para proceder a tramitar la solicitud del voto por correo ${ }^{53}$.

Gómez Cuenca, aun admitiendo que pueden darse situaciones extremas en las que las personas con discapacidad intelectual o mental no puedan manifestar por ningún medio, ni siquiera con apoyo o asistencia, sus preferencias electorales, defiende la postura contraria. En este sentido, considera que no deben contemplarse dichas situaciones como excepción en la ley, ni siquiera de manera muy restrictiva, porque le parece irrazonable privar del derecho a quien de facto no puede ejercerlo y porque el peligro que puede comportar su puesta en práctica dada la tendencia de los tribunales a hacer excepciones a la regla general con las normas de discapacidad ${ }^{54}$.

Nosotros somos de la opinión contraria y creemos que nuestra postura es compatible incluso con la propia CDPD, que exige que las personas con discapacidad puedan expresar libremente su voluntad política; lo cual, presupone la existencia previa de tal voluntad y que, como hemos visto, rechaza por completo la toma de decisiones por sustitución del discapacitado. Eso sí, debe quedar claro en la Ley Orgánica que se trata de una medida extrema, que únicamente cabría adoptar en los casos de inconsciencia o de absoluta falta de capacidad de decidir y querer, adoptada con todas las garantías, es

derecho de sufragio puede verse mi trabajo, $M^{\mathrm{a}}$. R. PÉREZ ALBERDI, El derecho fundamental a participar en los asuntos públicos, op. cit., pp. 106-187.

${ }^{53}$ J. GÓMEZ-RIESCO TABERNERO DE PAZ, "La privación del ejercicio de derecho de sufragio activo de las personas con capacidad modificada judicialmente. Comentario al Auto del Tribunal Constitucional 196/016, de 28 de noviembre”, Derecho Privado y Constitución, núm. 31, 2017, p. 267.

${ }^{54}$ P. CUENCA GÓMEZ, "El derecho de voto de las personas con discapacidad intelectual y psicosocial. La adaptación de la legislación electoral española a la Convención Internacional de Derechos de las Personas con Discapacidad”, op. cit., p. 202. 
decir, tras la evaluación judicial individualizada y proporcionada sobre la aptitud de la persona para expresar una opción política.

Ello impediría por completo la práctica judicial extendida en nuestro país (y (avalada por el ATC 196/2016)) de exigir a las personas con discapacidad conocimientos específicos sobre el sistema político, sobre las diferentes opciones electorales o que analizan la razonabilidad de la elección, basándose en otros fines distintos del respeto de la propia dignidad de la persona con discapacidad, como los perjuicios o daños que le pueda ocasionar ejercitar su derecho de voto (inexistentes, como es fácil de colegir), al correcto funcionamiento del sistema electoral y la democracia (inapreciables, en términos de proporcionalidad, 98.488 electores de un censo electoral de 36.520.913 electores, en las elecciones generales de junio de 2016) o la influenciabilidad de estos electores (cuando la influencia sobre los votantes es precisamente el objeto de la contienda electoral y es perseguible como delito o infracción electoral, al igual que la del resto de electores, en caso de ser indebida). Conocimientos que, como dijimos, no se exige al resto de los electores y supone un tratamiento discriminatorio adoptado exclusivamente en razón de la discapacidad.

\subsection{La omisión de toda regulación de las medidas y apoyos precisos para el ejercicio del sufragio activo por las personas con discapacidades intelectuales o psíquicas}

El reconocimiento de los derechos de participación política de las personas con discapacidad intelectual o mental se ha realizado sin prever ningún ajuste que les pueda facilitar la participación en igualdad de condiciones con el resto de los electores, pudiendo darse el caso de que una persona necesite de algún apoyo o asistencia personal. En este sentido, Martinez-Pujalte propone que se extienda el procedimiento de voto asistido del artículo 87.1 de la LOREG, previsto para los supuestos de discapacidad física o sensorial, a las personas con discapacidad intelectual o psíquica ${ }^{55}$. De esta manera, una persona de confianza del elector discapacitado podría acompañarle durante las operaciones electorales para ayudarle a asociar la papeleta electoral a opción política por la que quiere votar o con el proceso electoral correspondiente, dada la frecuente concurrencia de elecciones ${ }^{56}$.

Al margen de que se pudiera adoptar alguna medida de este tipo, creemos que en este punto resulta imprescindible extender la dimensión prestacional del derecho de sufragio. Los poderes públicos tienen la obligación de facilitar dicha participación a través, por ejemplo, de talleres de capacitación electoral que, en aplicación del principio de accesibilidad universal, podrían estar abiertos a todos los electores y no solo a aquellos

\footnotetext{
55 A. L. MARTÍNEZ-PUJALTE, Derechos fundamentales y discapacidad, op. cit., pp. 104-107.

${ }^{56}$ La Instrucción de la junta Electoral Central 5/2019, de 11 de marzo, sobre aplicación de la modificación de la LOREG llevada a cabo por la Ley Orgánica 2/2018, de 5 de diciembre, para garantizar el derecho de sufragio de todas las personas con discapacidad, parece admitir dicha posibilidad, aunque debería haber dejado más claro que se refiere a los electores con cualquier tipo de discapacidad, incluida la intelectual o mental, pues el caso de la discapacidad física o sensorial no ofrece ninguna duda interpretativa en el artículo 87.1 de la LOREG.
} 
con discapacidad intelectual o mental; la elaboración de Guías sobre el derecho al voto en "lenguaje fácil” o la adaptación del contenido de los programas electorales a ese mismo lenguaje. Todas estas iniciativas hasta el momento han partido de las asociaciones y organizaciones de colectivos con discapacidad. También habría que adaptar todas las informaciones electorales y campañas institucionales previstas en el RD 422/2011.

\section{3. ¿Y el sufragio pasivo? ¿Por qué no introducir cuotas electorales?}

Una última cuestión que ha olvidado por completo la reforma de la LOREG, a pesar de que el Comité de Derechos de Personas con Discapacidad había insistido en sus Observaciones Finales sobre España de 2011, es la referente a los apoyos, incluidos asistentes personales, de los cargos electivos con cualquier tipo de discapacidad.

De hecho, no encontramos en la legislación ninguna medida para facilitar el sufragio pasivo o el ejercicio de los cargos públicos representativos por parte de las personas con cualquier tipo de discapacidad. Podrían introducirse subvenciones o ayudas para contratar esos asistentes, costear desplazamientos especiales, adquirir materiales o programas informáticos necesarios para el desarrollo de sus funciones, como ha hecho el Reino Unido que desde 2015 prevé ayudas entre $250 £$ y $40.000 £$ para los candidatos con discapacidad $^{57}$.

Por último, para poner freno a las barreras sociales existentes respecto a las personas con discapacidad consideramos imprescindible la introducción de cuotas que obliguen a reservar un porcentaje, del $10 \%$ por ejemplo, de los puestos de las listas electorales a personas con discapacidad. Esta medida, como hemos visto, estaría plenamente justificada desde el punto de vista constitucional por no suponer discriminación prohibida por razón de discapacidad, sino un trato desigual dirigido a la parificación de este colectivo con el resto de la sociedad (artículo 9.2 CE) ${ }^{58}$. Tampoco incidiría sobre el principio de autoorganización de los partidos políticos que integra el contenido del derecho fundamental de asociación (artículo 22 CE), pues, como también ha señalado el Tribunal Constitucional, las cuotas electorales no inciden en las reglas de funcionamiento de los partidos, sino en su actividad externa, no siendo más que un requisito más para la validez de las listas electorales, como lo son su carácter de cerradas y bloqueadas o la exigencia de que su denominación no dé lugar a confusión ${ }^{59}$.

\footnotetext{
57 AGENCIA DE LA UNIÓN EUROPEA PARA LOS DERECHOS FUNDAMENTALES: Who will (not) get to vote in the 2019 European Parliament elections? Developments in the right to vote of people deprived of legal capacity in EU members States, op. cit., p.

58 Por todas, STC 3/2018, de 22 de enero, FJ 5.

${ }^{59}$ Por todas, STC 12/2008, de 29 de enero, Fj. 5. Me he extendido sobre esta cuestión en M ${ }^{\mathrm{a}}$. R. PÉREZ ALBERDI, El derecho fundamental a participar en los asuntos públicos, op. cit., pp. 177-178.
} 


\section{BIBLIOGRAFÍA}

AGENCIA DE LA UNIÓN EUROPEA PARA LOS DERECHOS FUNDAMENTALES: El derecho a la participación política para las personas con discapacidad: indicadores de derechos humanos, FRA, Luxemburgo, 2014.

-Who will (not) get to vote in the 2019 European Parliament elections? Developments in the right to vote of people deprived of legal capacity in EU members States, FRA, Luxemburgo, 2019.

ALONSO LÓPEZ, "Los ejes determinantes de las políticas de igualdad de oportunidades. La accesibilidad universal y el diseño para todos”, en: R. DE LORENZO y LÓPEZ BUENO, L. C. (Coords.), Tratado sobre discapacidad, Thomson Reuters Aranzadi, Madrid, 2007.

ÁLVAREZ GARCÍA, H., "La tutela constitucional de las personas con discapacidad”, Revista de Derecho Político, núm. 100, 2017.

ASIS ROIG, R. de, Sobre discapacidad y derechos, Dykinson, Madrid, 2013.

BARIFFI, F. J., “Corte Europea de Derechos Humanos: Ejercicio del derecho al voto de personas sujetas a un régimen de tutela (Caso Alajos Kiss vs. Hungría)”, en: F. J. BARIFFI (Coord.), Práctica clínica y litigación estratégica en discapacidad y Derechos Humanos: algunas experiencias de Iberoamérica, Dykinson, Madrid, 2013.

BARRAT ESTEVE, J., "Discapacitados mentales y participación política: el derecho de sufragio", en: G. ESCOBAR ROCA y A. PÉREZ TROYA (Dirs.): Ombudsman y colectivos en situación de vulnerabilidad. Actas del III Congreso Internacional del PRADPI, Tirant lo Blanch, Valencia, 2017.

BOTELLO HERMOSA, P., "El refuerzo de la curatela como medio idóneo de adaptación del artículo 12 de la Convención ONU sobre derechos de personas con discapacidad al Ordenamiento jurídico español”, Revista Crítica de Derecho Inmobiliario, núm. 749, 2015.

CAMPO IZQUIERDO, A. L., "Los procesos judiciales de capacidad a la luz de la Convención de Nueva York sobre los derechos de las personas con discapacidad”, La Ley Derecho de Familia. Revista jurídica sobre familia y menores, núm. 2, 2014.

CUENCA GÓMEZ, P., "El derecho de voto de las personas con discapacidad intelectual y psicosocial. La adaptación de la legislación electoral española a la Convención Internacional de Derechos de las Personas con Discapacidad”, Derechos y libertades, núm. 38, 2018.

DÍAZ ALABART, S., "El derecho de sufragio de las personas con discapacidad. La visión civilista”, Revista de Derecho Privado, núm. 96, 2012. 
GÁLVEZ MUÑOZ, L., El derecho de voto de los discapacitados y otras personas vulnerables, Tirant lo Blanch, Valencia, 2009.

— “El régimen de la participación electoral de las personas con discapacidad en los cuarenta años de democracia”, Revista de Derecho Político, núm. 100, 2013.

GÓMEZ-RIESCO TABERNERO DE PAZ, J., “La privación del ejercicio de derecho de sufragio activo de las personas con capacidad modificada judicialmente. Comentario al Auto del Tribunal Constitucional 196/016, de 28 de noviembre”, Derecho Privado y Constitución, núm. 31, 2017.

LEÓN ALONSO, M., “Los derechos de participación política de las personas con discapacidad: el derecho al voto”, Revista Europea de Derechos Fundamentales, núm. 24, 2014.

MARTÍNEZ-PUJALTE, A. L., Derechos fundamentales y discapacidad, Cinca, Madrid, 2015.

PALACIOS, A., El modelo social de discapacidad: orígenes, caracterización y plasmación en la Convención Internacional sobre los derechos de las personas con discapacidad, Cinca, Madrid, 2008.

—_El modelo social de discapacidad y su concepción como cuestión de derechos humanos”, Revista Colombiana de Ciencias Sociales, vol. 8, núm. 1, 2017.

PALACIOS, A. y BARIFFI, F. J., La discapacidad como una cuestión de derechos humanos. Una aproximación a la Convención Internacional sobre los derechos de las personas con discapacidad, Cinca, Madrid, 2007.

PASCUAL PLANCHUELO, V. C.; "El derecho de voto de las personas con discapacidad y, en especial, de las personas con discapacidad psíquica o intelectual en Derecho Internacional. Su recepción en España”, Revista Española de Discapacidad, 4 (1), 2017.

PÉREZ ALBERDI, Mª R., El derecho fundamental a participar en los asuntos públicos, Congreso de los Diputados, Madrid, 2013.

"La delimitación del derecho de sufragio activo por la el Tribunal Europeo de Derechos Humanos”, Revista de Derecho Político, núm. 88. 2013.

— “Privación a los condenados del sufragio en las elecciones al Parlamento europeo. El principio de "sufragio universal” como obligación impuesta por el Derecho Europeo al legislador nacional en la definición de la ciudadanía política de la Unión”, en: A. M. CARMONA CONTRERAS, Construyendo un estándar europeo de derechos fundamentales, Thomson Reuters Aranzadi, 2018. 
PRESNO LINERA, M. A., "La titularidad del derecho de participación política”, Boletín Mexicano de Derecho Comparado, núm. 104, 2002.

—_El derecho de voto como derecho fundamental” Revista Mexicana de Derecho Electoral, núm. 2, 2012.

RIVAS VAÑÓ. "Discapacidad intelectual y derecho al sufragio: la inacción del Tribunal Constitucional español”, en: V. CARUSO FONTÁN y $\mathrm{M}^{\mathrm{a}}$ R. PÉREZ ALBERDI, Diálogos judiciales en el sistema europeo de protección de derechos, Tirant lo Blanch, Valencia, 2018.

SÁNCHEZ-MOLINA, P., "El margen de apreciación nacional en las Sentencias del Tribunal Europeo de Derechos Humanos relativas al derecho de elecciones libres”, Estudios de Deusto, núm. 62 (I), 2014. 